\title{
Prion Properties of SOD1 in Amyotrophic Lateral Sclerosis and Potential Therapy
}

\author{
Caroline Sibilla and Anne Bertolotti \\ MRC Laboratory of Molecular Biology, Cambridge CB2 0QH, United Kingdom \\ Correspondence: aberto@mrc-Imb.cam.ac.uk
}

Amyotrophic lateral sclerosis (ALS) is a devastating and rapidly progressive neurodegenerative disease caused by the deterioration of motor neurons. The first symptoms of ALS always begin at a focal but variable site and consistently spread to neighboring regions, suggesting that neurodegeneration in ALS is an orderly and propagating process. Like other neurodegenerative diseases, misfolding of a specific protein is central to ALS. SOD1, the major constituent of the protein deposits in some familial and sporadic forms of ALS, propagates its misfolded conformation like prions, providing a plausible molecular basis for the focality and spreading of muscle weakness in ALS. Because protein misfolding is a common cause of diverse neurodegenerative diseases, strategies aimed at boosting a cell's ability to cope with misfolded proteins could lead to therapeutics to combat these devastating age-related proteinopathies.

In the 1890s, Jean-Martin Charcot first described amyotrophic lateral sclerosis (ALS) with remarkable detail and completeness (Charcot 1890). His characterization of the disease is still valid today-progressive degeneration of upper and lower motor neurons resulting in advancing muscle weakness, spasticity, atrophy, and paralysis. ALS begins in adult life, similar to other neurodegenerative diseases like $\mathrm{Alz}$ heimer's (AD), Parkinson's (PD), and Huntington's (HD). However, unlike AD, PD, and HD, which have a clinical course of decades, the progression of ALS is fast and furious: $50 \%$ of patients die within 1.5 years of disease onset, although some individuals occasionally survive for more than 10 years (Kiernan et al. 2011). PrP prion diseases such as Creutzfeldt-Jakob disease (CJD) are similarly aggressive and rapid, leading to death within 1 year by respiratory fail- ure. Like most other neurodegenerative diseases, there are no treatments to prevent or halt the progression of ALS, and these types of diseases are becoming more prevalent in an aging society.

ALS is characterized by muscle weakness, which always begins at a focal point, but the body region involved is highly variable between individuals. From the site of onset, the symptoms spread contiguously to adjacent regions. This unique feature of ALS was initially reported by Gowers (1892) and more recently modeled by Ravits and La Spada (2009). The spreading of the disease suggests that neurodegeneration may follow an orderly and propagating process. In recent years, the molecular mechanism that explains the key clinical features of ALS has been shown to be similar to the molecular basis of prion diseases (Figs. 1 and 2).

Editor: Stanley B. Prusiner

Additional Perspectives on Prion Biology available at www.cshperspectives.org

Copyright (C) 2017 Cold Spring Harbor Laboratory Press; all rights reserved; doi: 10.1101/cshperspect.a024141

Cite this article as Cold Spring Harb Perspect Biol 2017;9:a024141 


\section{Sibilla and A. Bertolotti}
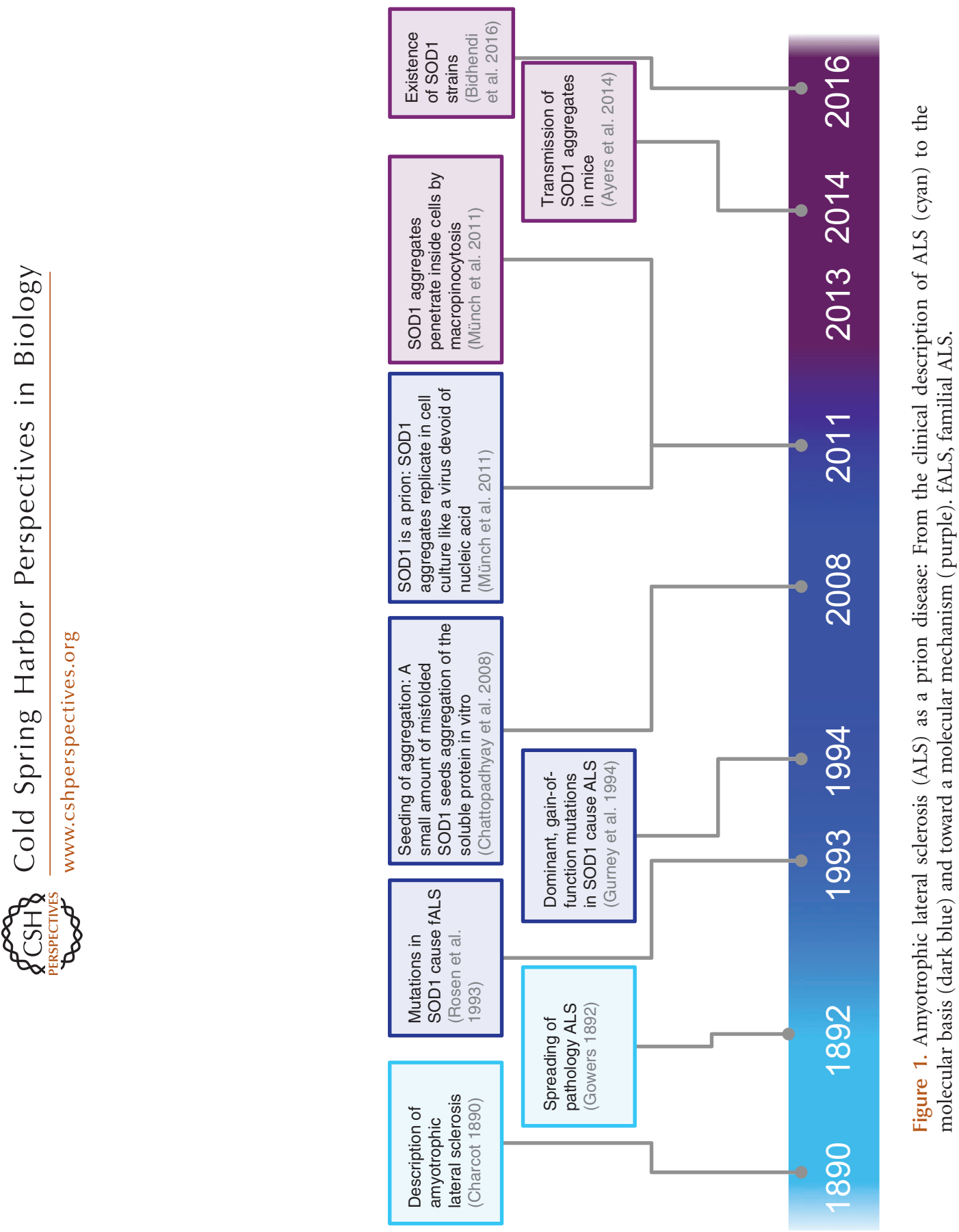


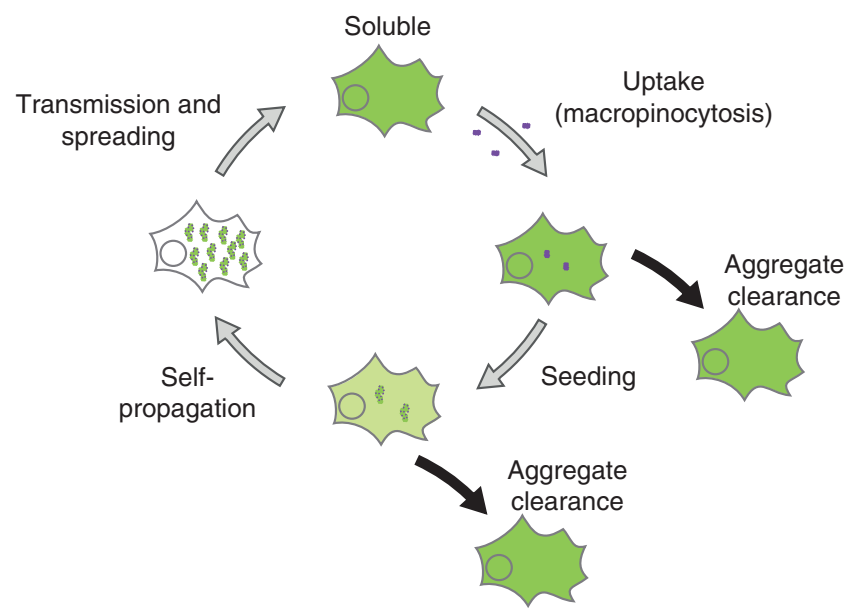

Figure 2. The vicious cycle: prion propagation of aggregates. Aggregates made of SOD1 (Münch et al. 2011) or tau (Holmes et al. 2013; Sanders et al. 2014) can enter cells by macropinocytosis and access the cytosol. Once in the cytosol, protein quality control systems normally clear aggregates, but prions escape protein quality control systems to corrupt the conformation of the normally soluble proteins. Once this has occurred, aggregates propagate and are transmitted and spread from cell to cell.

The etiology of ALS is unknown; however, similar to most other neurodegenerative diseases, ALS is primarily a sporadic disease, with about $10 \%$ of ALS cases attributable to inherited mutations. An increasing number of causative genes, including SOD1, TDP-43, FUS/TLS, C9ORF72, and others, have been identified (Bettencourt and Houlden 2015). The clinical manifestations of sporadic and familial ALS (fALS) are the same, suggesting a common mechanism. Therefore, studying rare forms of the disease may reveal mechanisms relevant to forms that are more common. The SOD1 gene encodes the $\mathrm{Cu} / \mathrm{Zn}$ superoxide dismutase 1 (SOD1), a free-radical scavenging enzyme. SOD1 was the first ALS gene to be identified (Rosen et al. 1993) and is dominantly inherited (mostly missense mutations). Mutations in SOD1 account for $\sim 20 \%$ of familial forms of ALS. It is well established that SOD1 mutations lead to a toxic gain of function of SOD1 protein (Gurney et al. 1994) and that loss of SOD1 activity is not associated with disease pathogenesis. Indeed, mice lacking SOD1 do not develop motor neuron diseases (Reaume et al. 1996). In contrast, expression of mutant SOD1 in transgenic mice recapitulates the characteristics of the human disease faithfully—progressive dep- osition of SOD1 and motor neuron loss leading to paralysis and death (Gurney et al. 1994; Wang et al. 2009).

\section{PROTEIN MISFOLDING: THE MOLECULAR BASIS OF ALS}

Like prion diseases, $\mathrm{AD}, \mathrm{PD}, \mathrm{HD}$, and ALS are diseases caused by the deposition of one or two misfolded proteins. The disease-causing proteins are $\beta$-amyloid and tau in $\mathrm{AD}, \alpha$-synuclein in $\mathrm{PD}$, huntingtin in $\mathrm{HD}$, and $\mathrm{PrP}$ in transmissible prion encephalopathies. TDP-43 may be the major constituent of deposits in most sporadic ALS cases (Neumann et al. 2006). In SOD1 fALS, the major constituent of protein deposits is mutant SOD1 (Valentine et al. 2005). Interestingly, in some other fALS and sporadic cases, in which no mutations in SOD1 are present, wild-type SOD1 has been found in inclusions (Rotunno and Bosco 2013).

SOD1 is an abundant and ubiquitously expressed 153-residue protein, existing as a homodimer of $32 \mathrm{kDa}$. Each monomer is highly structured, consisting mostly of an eight-stranded $\beta$ barrel in a Greek-key fold and two large loops, one of which is the metal binding loop that binds one copper and one zinc ion (Valentine 
et al. 2005). The monomers of SOD1 contain an intramolecular disulfide bridge, which increases protein stability. The native SOD1 protein has exceptional thermodynamic and kinetic stabilities, with reported melting temperatures in the range $85^{\circ} \mathrm{C}-100^{\circ} \mathrm{C}$, and is enzymatically stable in $8 \mathrm{M}$ urea, $3.2 \mathrm{M}$ guanidine $\mathrm{HCl}$, and $1 \%$ sodium dodecyl sulfate (SDS) (Valentine et al. 2005). Even more remarkably, SOD1 enzymatic activity was reported to survive more than 3000 years after mummification, as an active SOD1 fragment has been recovered from an Egyptian mummy (Weser et al. 1989). Despite the extraordinarily intrinsic stability of the native SOD1 enzyme, mutations in SOD1 can destabilize the protein and induce misfolding and subsequent aggregation (Nordlund and Oliveberg 2008). Similarly, aberrant oxidation or posttranslational modification can have aggregation-prone effects on wild-type SOD1 in vitro (Rotunno and Bosco 2013).

To date, 183 mutations have been identified in SOD1, most of which are missense and dominantly inherited mutations, affecting nearly every amino acid of the protein. SOD1 mutations can have diverse effects on the properties of the protein, such as altering stability, metal binding, and enzymatic activity. Interestingly, many mutations seem to have no measurable effect on the protein (Valentine et al. 2005). Despite this, the diverse mutations can promote aggregation of the protein. How this occurs has been a mystery for a long time. Initially, it was assumed that different mutations cause aggregation by specific mechanisms (Shaw and Valentine 2007). However, we found that diverse ALS-causing mutations share a common defect: They have an increased propensity to expose hydrophobic surfaces that are normally buried in the interior of the native state (Münch and Bertolotti 2010). Importantly, many SOD1 mutants that are natively folded like the wild-type form do not constitutively expose hydrophobic surfaces but have a propensity to do so when destabilized (Münch and Bertolotti 2010). These results reconciled the seemingly diverse effects of ALS-causing mutations into a unifying mechanism.

Mutant SOD1 is expressed throughout the life of individuals, although the disease mani- fests in mid-adult life (Kiernan et al. 2011). Even in transgenic mice overexpressing an ALS-causing SOD1 mutant, aggregation is an age-dependent process (Johnston et al. 2000; Wang et al. 2009). In cells, overexpression of diverse ALS-causing SOD1 mutants does not lead to their aggregation and formation of deposits that are characteristic of the disease (Johnston et al. 2000; Münch et al. 2011). Although the ALS-causing SOD1 mutations render the protein prone to misfold, it is soluble in cell culture and in young mice. This may also be the case for many years in individuals with SOD1 mutations before the misfolded proteins accumulate in aged cells, perhaps as a consequence of defects in protein quality control mechanisms.

The key features of ALS - namely, the focality of muscle weakness onset with subsequent spreading of the symptoms in an orderly manner to neighboring body regions, the variability of site and age of onset, and the central role of protein misfolding-have suggested the following model: The site of disease onset may correspond to an initial site of protein misfolding. Following initial onset of misfolding, the misfolded protein may spread as a pathogenic agent from the site of onset to adjacent sites. This led us to investigate whether SOD1 shared some properties of prions.

\section{PRION-LIKE PROPAGATION OF SOD1}

A prion is a protein that exists in different conformations, one of which is self-propagating and transmissible (Prusiner 1998). A prion propagates by an autocatalytic process in which it imposes its abnormal conformation on a normally folded counterpart, requiring no other proteins, factors, or genetic material.

In the test tube, addition of preformed SOD1 aggregates can accelerate or seed aggregation of the soluble protein (Chattopadhyay et al. 2008), indicating that like prions, misfolded SOD1 has the ability to corrupt the folding of the soluble protein. Similar properties have been reported for the diverse misfolded proteins associated with neurodegenerative disease (Eisenberg and Jucker 2012). Indeed, misfolded 
proteins can act as seeds in an aggregation reaction that converts native proteins into misfolded pathological forms in a nucleated polymerization reaction that results in the formation of fibrils (Eisenberg and Jucker 2012). However, a cell is not a test tube. SOD1 is an intracellular cytosolic protein. For the seeding and spreading of aggregates to occur between cells, as is the case for prions, penetration of aggregates inside the cell is required. To test for such a possibility, we prepared aggregates with recombinant, highly purified protein and asked: Can such aggregates enter neuronal cells? It turned out to be the case: SOD1 aggregates can penetrate cells and induce aggregation of the otherwise soluble cellular protein. Remarkably, once induced, aggregation persists and is transmissible from cell to cell (Münch and Bertolotti 2011, 2012; Münch et al. 2011). This revealed that SOD1 behaves like a prion: It has the ability to replicate its aberrant conformation indefinitely, like a virus, but it is only composed of a protein (Fig. 2). This work shows that the protein-only mode of transmission of information, the hallmark of prions, is not restricted to PrP in mammals but is broader than previously recognized.

\section{PRION-LIKE PROPERTIES OF SOD1}

\section{Uptake of SOD1 Aggregates}

To study the fate of exogenous aggregates in cells, SOD1 aggregates made of highly purified and recombinant protein were labeled with fluorescent dyes (Münch et al. 2011) and directly added to the culture media of neuronal cells. Rapidly after their inoculation, aggregates had penetrated in virtually all of the cells. Indeed, flow cytometry and confocal microscopy analyses detected the fluorescently labeled protein aggregates in nearly $100 \%$ of the cells.

Recent follow-up studies corroborated these findings: Aggregates recovered from conditioned media of NSC-34 cells transiently transfected with a plasmid encoding wild-type or mutant green fluorescent protein (GFP)-SOD1 and applied to naïve cells can penetrate inside cells (Grad et al. 2014). Furthermore, two studies show that recombinant SOD1 can be taken up by cells detected by flow cytometry and visualized by confocal microscopy (Grad et al. 2014; Zeineddine et al. 2015), as previously seen (Münch et al. 2011).

The finding that aggregates can penetrate inside cells efficiently came as a surprise. Because this process was efficient, it created an opportunity to study the underlying mechanisms. The uptake of SOD1 occurs via an active process because depletion of ATP prevents aggregate uptake (Münch et al. 2011). We did not obtain any evidence that aggregates could directly penetrate through the plasma membrane (unpublished results). Interfering with actin polymerization using cytochalasin A or D dramatically reduced aggregate uptake, showing that aggregates enter cells by an endocytic route (Münch et al. 2011). Confirming this result, endocytic vesicles labeled with lipophilic FM 4-64FX dye contained fluorescent aggregates (Münch et al. 2011). Endocytosis occurs via different mechanisms in mammalian cells. The pathway responsible for SOD1 aggregate uptake was elucidated using a combination of approaches. Key components of the diverse endocytosis pathways were inhibited using pharmacological inhibitors, dominant negative mutants, or genetically modified cells, and SOD1 aggregate uptake was monitored by flow cytometry. The comprehensive analysis of the different endocytic pathways revealed that extracellular mutant SOD1 aggregate uptake was not mediated by clathrin, dynamin, caveolin, or flotillin. However, inhibitors of macropinocytosis prevented the uptake of SOD1 aggregates, showing that SOD1 aggregates use macropinocytosis to enter cells (Münch et al. 2011). These findings were confirmed in two recent studies reporting that uptake of SOD1-GFP into NSC-34 cells was prevented by macropinocytosis inhibitors, but not by inhibitors of the other major endocytic routes, as measured by flow cytometry (Grad et al. 2014; Zeineddine et al. 2015).

Seeding of Aggregation of the Soluble and Cellular Protein by Preformed Aggregates

SOD1 aggregates enter cells using macropinocytosis, but they do not stay in macropino- 
somes. In fact, aggregates rapidly escape micropinosomes to access the cytosol, where they become ubiquitinated (Münch et al. 2011) just like the deposits in ALS. In the cytosol, SOD1 aggregates corrupt the otherwise soluble cellular protein. Importantly, the intermolecular transmission of misfolding has also been reported between SOD1 mutant and wild type (Grad et al. 2011). In stable cells expressing mutant SOD1 fused to GFP, the protein appears diffuse throughout the cytosol and nucleus, indicating that it is soluble. Adding extracellular recombinant mutants provokes the coalescence of the otherwise soluble mutant SOD1-GFP into puncta in the cytosol and are excluded from the nucleus, showing that exogenous recombinant mutant SOD1 aggregates can seed aggregation of endogenous overexpressed SOD1 (Fig. 2) (Münch et al. 2011).

Similar observations of aggregate uptake and seeding have been reported with diverse proteins associated with neurodegenerative diseases (Jucker and Walker 2011). Brain homogenates containing $A \beta-$ or tau-induced aggregation of the then-soluble mouse peptide or protein, respectively (Kane et al. 2000; MeyerLuehmann et al. 2006; Clavaguera et al. 2009). When inoculated into cells, aggregates made of polyglutamine peptides, tau, or $\alpha$-synuclein also seeded aggregation of the otherwise soluble intracellular proteins (Danzer et al. 2007, 2009; Desplats et al. 2009; Frost et al. 2009; Ren et al. 2009).

Aggregation Induced by Prions Is Persistent and Self-Propagating

The defining property of prions is their ability to replicate their aberrant conformation indefinitely (Prusiner 1998). The prion conversion must be a rare event because organisms have evolved efficient and sophisticated protein quality-control mechanisms that normally combat protein aggregation (Schneider and Bertolotti 2015). Once a misfolded protein is produced, as a result of a biosynthetic error or insult, cells will normally react rapidly by either refolding or degrading the potentially harmful protein (Schneider and Bertolotti 2015). A prion must somehow escape the surveillance of the qualitycontrol system and persist for a sufficient period of time to corrupt the normal folding of its cellular counterpart. Once past this initial seeding event, aggregates need to continue to be amplified exponentially for a prion to propagate (Fig. 2).

Thus, what defines a prion is not only its ability to corrupt the conformation of the soluble conformer of a protein, but also its ability to evade the protein quality-control system (Figs. 2 and 3). Misfolded proteins are produced all the time in cells, but neurodegenerative diseases appear later in life. Most of the time, cells efficiently handle misfolded proteins to avoid disease, but in some rare cases, a protein of abnormal conformation persists and propagates its abnormal shape. This is the case with prions: a protein-only infectious agent (Prusiner 1998). Like prions, when aggregation of mutant SOD1 has been induced with recombinant aggregates, it persists and propagates (Münch et al. 2011). If self-propagation defines a prion, then SOD1 is a prion (Münch and Bertolotti 2011).

\section{Cell-to-Cell Transfer}

Just like prions, SOD1 aggregates can transfer from cell to cell (Münch et al. 2011). We found that SOD1 cell-to-cell transfer of aggregates dramatically decreases when increasing the volume of cell culture media, showing that transfer of aggregates depends on the release of aggregates into the extracellular space rather than cellto-cell contact (Münch and Bertolotti 2011). Aggregates can transfer from conditioned media obtained from the culture of cells containing labeled aggregates (Münch and Bertolotti 2011). Similarly, SOD1 particles could be transferred to new NSC-34 cells via conditioned media (Grad et al. 2014). In the later study, aggregates were proposed to be released from NSC-34 cells by two routes: via exosomes or as a naked species (Grad et al. 2014). The finding that transfer of aggregates can be reduced by antiSOD1 antibodies (Grad et al. 2014) argues that a predominant fraction of the transferring species are accessible to antibody binding. Similar cell-to-cell transfer may occur in humans 
Prion Properties of SOD1 in ALS and Potential Therapy

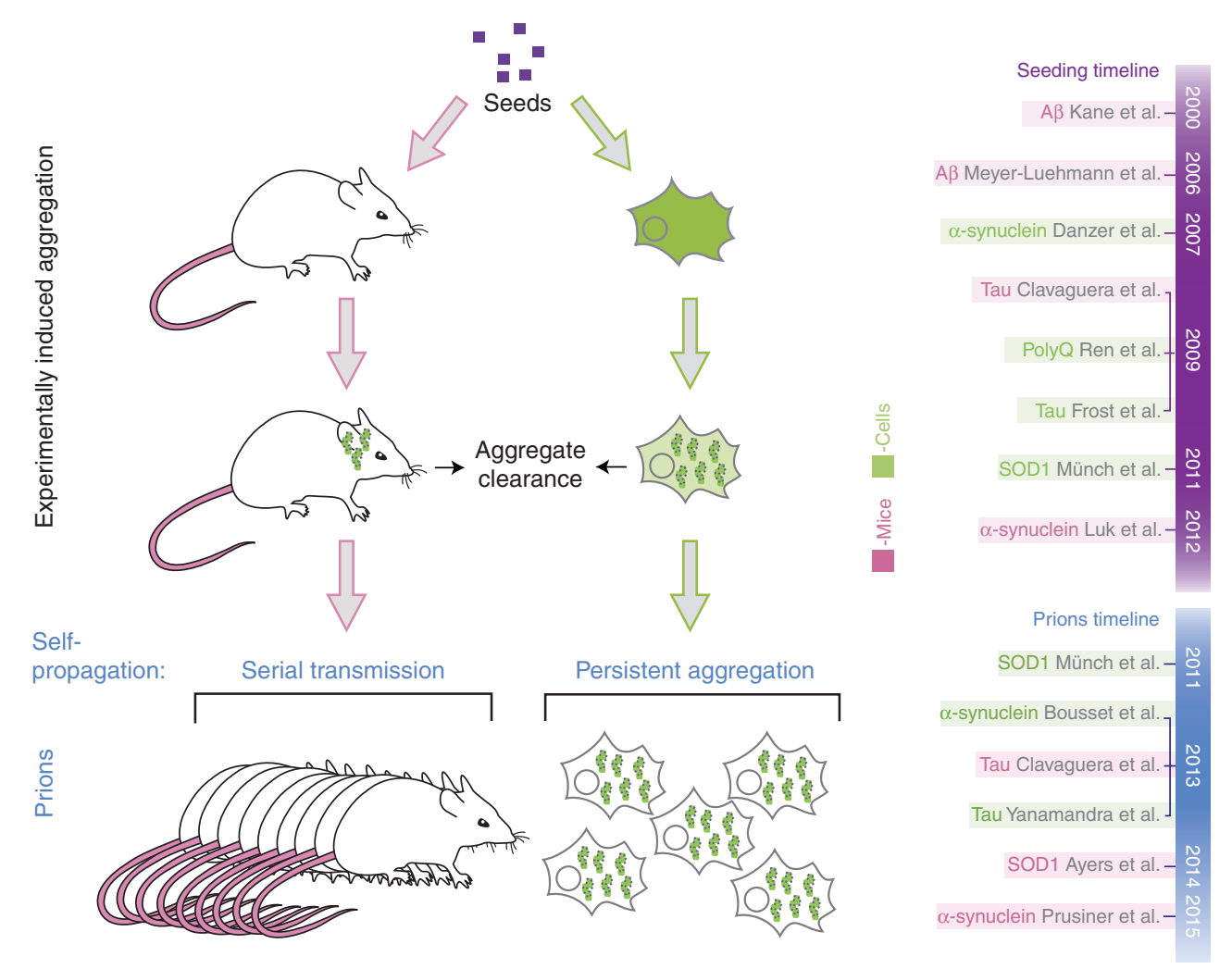

Figure 3. Experimental induction of aggregation. Seeding of aggregation has been induced experimentally in mouse and cell culture models. Seeds can be removed by the quality control mechanisms of the cellular host (aggregate clearance) or persist and corrupt the folding of the host protein. Prions not only have the ability to seed aggregation of their soluble counterpart but also are amplified in a host. The ability to replicate an abnormal conformer of a protein in a host defines prions. On the right is shown a timeline of the discoveries of the seeding and prion properties of misfolded proteins.

and explain the focality and spreading of neurodegeneration in ALS. Interestingly, transmission of aggregates has been suggested in humans for $\alpha$-synuclein, in which aggregates have been observed in grafted neurons (Li et al. 2008).

\section{In Vivo Transmission of SOD1 Aggregates}

A recent study has investigated if SOD1 mutant aggregates can be transmitted from mouse to mouse to induce ALS (Ayers et al. 2014). This study used G85R-yellow fluorescent protein (YFP) mice, which in the heterozygous state are asymptomatic, but in the homozygous state, develop an ALS phenotype associated with the accumulation of fluorescent inclusions in the spinal cord. These heterozygous mice were in- traspinally injected with spinal-cord homogenates from heterozygous G93A terminally sick, paralyzed mutant mice (Ayers et al. 2014). The injected mice developed motor neuron disease with widespread YFP inclusions in the spinal cord, brainstem, and thalamus. To further assess transmissibility, spinal-cord homogenates from the paralyzed recipient G85R-YFP mice were used as inoculum to inject into the spinal cords of P0 G85R-YFP mice. Although the first passage induced an ALS phenotype in only a subset of animals, the second passage produced an ALS phenotype in all of the recipient G85R-YFP mice (Ayers et al. 2014). This finding indicates that the SOD1 prion has been amplified between the passages, which is a hallmark property of prions. 


\section{TO BE, OR NOT TO BE, A PRION}

A prion is a misfolded protein that induces a self-propagating conformational change in the soluble counterpart. There is abundant evidence from many laboratories indicating that aggregation of proteins associated with neurodegenerative diseases can be induced experimentally (Jucker and Walker 2011). But are they all prions?

To assess whether the induced aggregates are prions, it is important to examine the ability of induced aggregates to persist and propagate in a host (Fig. 3).

Seeds transduced into cells or in animals can have several fates. Most frequently, quality control mechanisms in the host cells efficiently remove the seeds: The misfolded proteins will either be refolded or degraded (Fig. 3). If a seed persists long enough, it may interact with the host protein, corrupting its folding and resulting in aggregate growth. Aggregates may continue to grow upon recruitment of soluble monomers. However, large aggregates may not be transmissible. It is only if the induced aggregates replicate and are amplified in a host that they are prions. Therefore, it is important to assess whether induced aggregates are amplified in a host or not.

Seeding experiments in cells or mice do not distinguish whether seeds grow into a bigger aggregate in a host or if they are amplified. Amplification of prions can be assessed in cell-culture models by examining if the induced aggregates persist in the vast majority of cells long after the seeds have been removed (longer than a month and for more than several passages). In mice, self-propagation of prions can be assessed by serial transmission experiments similar to those used to evaluate the presence of a viral agent. If a prion or a virus replicates in a host, it produces many more infectious units than the initial inoculum.

Most proteins associated with neurodegenerative diseases can seed aggregation of their soluble counterparts (Jucker and Walker 2011). Are they all prions? SOD1 aggregates are selfpropagating (Münch et al. 2011). In that sense, SOD1 is a prion (Münch and Bertolotti 2011;
Prusiner 2012). Indeed, like a virus, SOD1 aggregates penetrate and are amplified in cells (Münch et al. 2011). In a similar cell-culture model that revealed the prion properties of SOD1, $\alpha$-synuclein (Bousset et al. 2013) and tau (Yanamandra et al. 2013) aggregates were also found to self-propagate their misfolded conformation like prions (Fig. 3). Like SOD1 aggregates, tau aggregates enter cells by macropinocytosis (Holmes et al. 2013), suggesting that different aggregates may use the same mechanisms to infect cells.

In mice, persistence and amplification of the induced aggregates can be assessed by serial transmission of aggregates. Tau (Clavaguera et al. 2013), SOD1 (Ayers et al. 2014), A $\beta$ (Watts et al. 2014), and $\alpha$-synuclein (Prusiner et al. 2015) aggregates can be serially transmitted, indicating that these proteins can adopt prion properties (Fig. 3). Another important feature of prions is the existence of strains. Different SOD1 strains have recently been reported further supporting the notion that misfolded SOD1 is a prion (Bidhendi et al. 2016).

\section{TOWARD RATIONAL THERAPEUTICS}

Prion diseases were thought to be unique for a long time because of the infectious nature of prions, but this view has changed dramatically in recent years, with a large body of evidence indicating that most misfolded proteins associated with neurodegenerative diseases share at least some of the defining properties of prions (Prusiner 2012). The idea of a common mechanism at the origin of diverse diseases is attractive because it could lead to a common therapy.

The deposition of misfolded proteins is a defining feature of many age-dependent human diseases, including the increasingly prevalent neurodegenerative diseases. Cells normally strive to ensure that proteins are correctly folded and have mechanisms to combat misfolded proteins. However, cellular defense systems seem to gradually fail with age, leading to the accumulation of misfolded proteins, which has devastating consequences for individual cells and the entire organism (Morimoto and Cuervo 2014; Vilchez et al. 2014). In principle, improv- 
ing a cell's ability to deal with misfolded proteins should represent a generic approach to reducing the pathology in diverse protein-misfolding diseases.

Our laboratory has recently validated this idea by identifying an approach that rescues cells from protein-misfolding insults (Tsaytler et al. 2011). When applied in mice, the same approach prevented two distinct neurodegenerative diseases: SOD1-ALS and CMT1B (Das et al. 2015). Our ability to prevent neurodegenerative diseases in mice emanates from the knowledge of the mechanisms that cells use to combat misfolded proteins.

A first line of defense against a variety of insults consists of attenuating protein synthesis by phosphorylating the $\alpha$-subunit of eukaryotic translation initiation factor 2 (eIF2 $\alpha$ ) (Ron and Harding 2007). Whereas this response is vital for cell survival, it is also vital that eIF $2 \alpha$ phosphorylation is only transient because a persistent inhibition of protein synthesis would be lethal. To ensure the reversibility of eIF $2 \alpha$ phosphorylation, mammals have evolved two selective eIF $2 \alpha$ phosphatases, composed of a catalytic subunit PP1c bound to one of two regulatory subunits: the stress-induced PPP1R15A (R15A) (Novoa et al. 2001) or the constitutive PPP1R15B (R15B) (Fig. 4) (Jousse et al. 2003). We found that a small molecule, Guanabenz, selectively binds and inhibits R15A, thereby prolonging eIF2 $\alpha$ phosphorylation and translation attenuation that follows stress (Tsaytler et al. 2011). Importantly, because Guanabenz selectively binds and inhibits R15A but not $\mathrm{R} 15 \mathrm{~B}$, translation attenuation is only transiently prolonged and thus not lethal. The folding capacity of cells depends on the availability of chaperones, and it is inversely correlated with rates of protein synthesis (Fig. 4) (Schneider and Bertolotti 2015). By decreasing the rates of protein synthesis, Guanabenz increases the availability of chaperones, thereby correcting folding defects and rescuing cells from protein-misfolding stress (Tsaytler et al. 2011). Although this approach is potent in res-

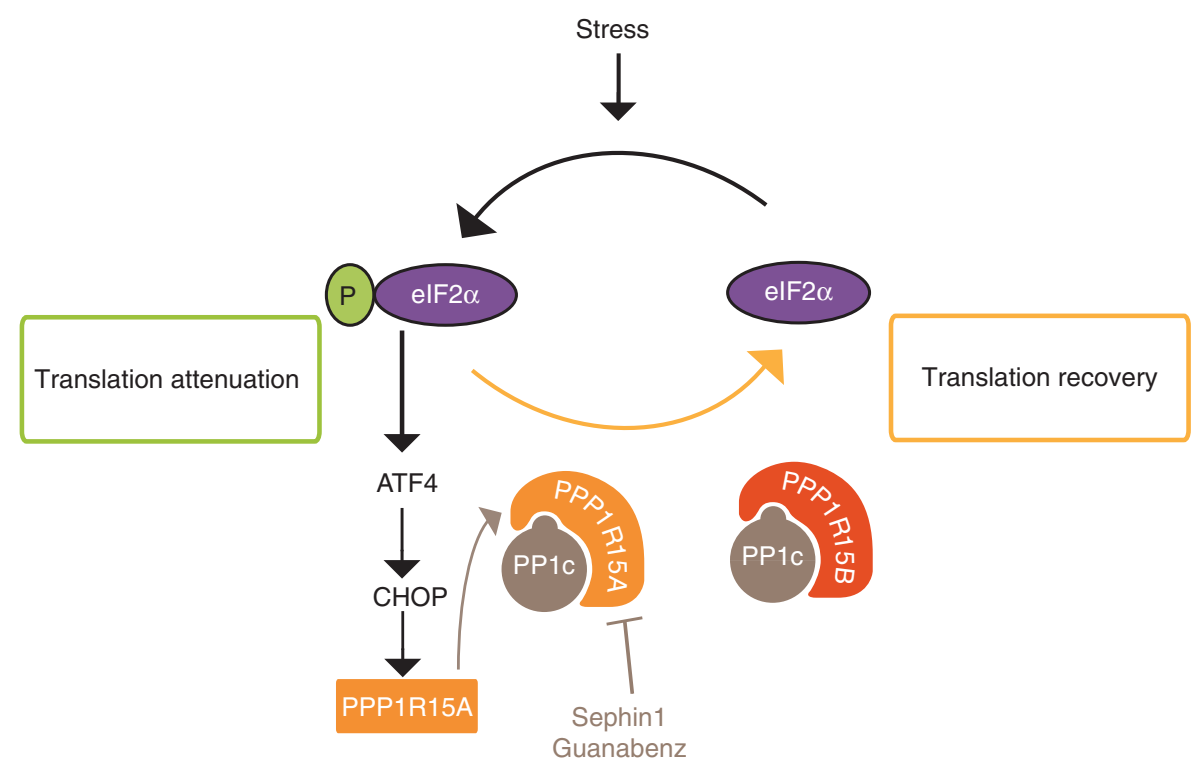

Figure 4. Guanabenz and Sephin1 are selective PPP1R15A inhibitors. Guanabenz and Sephin1 safely fine-tune protein synthesis by selectively binding and inhibiting the regulatory subunit of the stress-induced eIF $2 \alpha$ phosphatase composed of PPP1R15A and PP1c (Tsaytler et al. 2011; Das et al. 2015). Guanabenz and Sephin1 spare the constitutive eIF2 $\alpha$ phosphatase PPP1R15B-PP1c, thereby avoiding persistent eIF2 $\alpha$ phosphorylation, which would be lethal. Sephin 1 is orally available and safely prevents two unrelated neurodegenerative diseases, Charcot-Marie-Tooth 1B (CMT-1B) and SOD1-ALS, in mice (Das et al. 2015). 
cuing cells from the deleterious accumulation of misfolded proteins, Guanabenz could not be used as a selective R15A inhibitor in vivo because it has another, undesirable activity: It is a potent $\alpha$-adrenergic agonist (Holmes et al. 1983), which has side effects such as drowsiness, and even coma, at high doses in humans (Hall 1985).

Therefore, we aimed to engineer out the adrenergic activity of Guanabenz and identified Sephin1, a selective inhibitor of R15A suitable for in vivo studies (Das et al. 2015). Sephin1 is orally available, crosses the blood-brain barrier, and reaches concentrations in the brain that are predicted to be sufficient to inhibit R15A based on in vitro studies (Das et al. 2015). Sephin1 was designed in the hope that it would be useful to prevent protein-misfolding diseases. Indeed, it almost completely prevents SOD1ALS in mice as well as an unrelated proteinmisfolding disease, Charcot-Marie-Tooth 1B (CMT-1B) (Das et al. 2015). Sephin1 prevents weight loss, motor dysfunction, motor neuron loss, and aggregation of SOD1 (Das et al. 2015). Sephin1 also prevents the motor, morphological, and molecular defects of CMT-1B mice (Das et al. 2015). This is achieved without side effects, because of the selectivity of the inhibitor for R15A and because knocking out the R15A gene is not deleterious in mice (Kojima et al. 2003). This is important because neurodegenerative diseases are slowly progressive in most cases, and, therefore, there is a double challenge when searching for a therapeutic strategy: Efficacy needs to be achieved without side effects.

The idea that $R 15 A$ could be a therapeutic target is supported by genetic experiments from different groups. Deletion of one allele of PERK, one of the kinases that phosphorylates eIF $2 \alpha$, accelerates disease progression in an ALS-SOD1 mouse model, in contrast to nontransgenic mice lacking one allele of PERK, which are healthy (Wang et al. 2011). Importantly, genetic inactivation of $R 15 A$ has the opposite effect and ameliorates the disease (Wang et al. 2014). It is important to note that $R 15 \mathrm{~A}$ inhibition protects mice from ALS caused by the SOD $1{ }^{\mathrm{G} 93 \mathrm{~A}}$ mutant (Das et al. 2015), whereas mice lacking R15A are protected from ALS caused by a different
SOD1 mutant, SOD ${ }^{\mathrm{G} 85 \mathrm{R}}$ (Wang et al. 2014). Thus, R15A appears to be a valid therapeutic target in different mouse models of SOD1ALS. In the future, it will be important to determine how many diseases can be prevented by inhibiting R15A.

\section{CONCLUDING REMARKS}

The recently discovered prion, or prion-like, properties of proteins at the origin of various neurodegenerative diseases presents a common feature among diseases that were initially thought to be distinct. At the molecular and mechanistic levels, it is now clear that important insights into the etiology of these diverse neurodegenerative diseases have been uncovered by studying rare forms of these disorders. SOD1ALS represents only a fraction of ALS cases, but because many neurodegenerative diseases are caused by abnormal protein folding, the study of one protein-misfolding disorder sheds light on the molecular basis of such other diseases. Because protein misfolding is central to neurodegenerative disease, strategies aimed at correcting protein-folding defects are likely to be useful in preventing or halting these diseases. Our laboratory has recently provided the proof-ofprinciple that boosting natural cellular-defense mechanisms against misfolded proteins can lead to effective and safe approaches to preventing neurodegeneration.

\section{ACKNOWLEDGMENTS}

We are grateful to Laura Luh and Kim Schneider for comments on this manuscript and to the LMB Visual Aids facility for help with illustrations. The Bertolotti laboratory is funded by the Medical Research Council (U.K.), the European Research Council (ERC) under the European Union's Seventh Framework Programme (FP7/2007-2013)/ERC grant 309516, and the Motor Neurone Disease Association (U.K.).

\section{REFERENCES}

Ayers JI, Fromholt S, Koch M, DeBosier A, McMahon B, Xu G, Borchelt DR. 2014. Experimental transmissibility of 
mutant SOD1 motor neuron disease. Acta Neuropathol 128: 791-803.

Bettencourt C, Houlden H. 2015. Exome sequencing uncovers hidden pathways in familial and sporadic ALS. Nat Neurosci 18: 611-613.

Bidhendi EE, Bergh J, Zetterström P, Andersen PM, Marklund SL, Brännström T. 2016. Two superoxide dismutase prion strains transmit amyotrophic lateral sclerosis-like disease. J Clin Invest 126: 2249-2253.

Bousset L, Pieri L, Ruiz-Arlandis G, Gath J, Jensen PH, Habenstein B, Madiona K, Olieric V, Böckmann A, Meier $\mathrm{BH}$, et al. 2013. Structural and functional characterization of two $\alpha$-synuclein strains. Nat Commun 4: 2575.

Charcot JM. 1890. Lecons sur les maladies due systeme nerveux, 3 Vols. Bureau du Progres Medical, Paris, 1894.

Chattopadhyay M, Durazo A, Sohn SH, Strong CD, Gralla EB, Whitelegge JP, Valentine JS. 2008. Initiation and elongation in fibrillation of ALS-linked superoxide dismutase. Proc Natl Acad Sci 105: 18663-18668.

Clavaguera F, Bolmont T, Crowther RA, Abramowski D, Frank S, Probst A, Fraser G, Stalder AK, Beibel M, Staufenbiel M, et al. 2009. Transmission and spreading of tauopathy in transgenic mouse brain. Nat Cell Biol 11: 909-913.

Clavaguera F, Akatsu H, Fraser G, Crowther RA, Frank S, Hench J, Probst A, Winkler DT, Reichwald J, Staufenbiel M, et al. 2013. Brain homogenates from human tauopathies induce $\tau$ inclusions in mouse brain. Proc Natl Acad Sci 110: 9535-9540.

Danzer KM, Haasen D, Karow AR, Moussaud S, Habeck M, Giese A, Kretzschmar H, Hengerer B, Kostka M. 2007. Different species of $\alpha$-synuclein oligomers induce calcium influx and seeding. J Neurosci 27: 9220-9232.

Danzer KM, Krebs SK, Wolff M, Birk G, Hengerer B. 2009. Seeding induced by $\alpha$-synuclein oligomers provides evidence for spreading of $\alpha$-synuclein pathology. J Neurochem 111: 192-203.

Das I, Krzyzosiak A, Schneider K, Wrabetz L, D’Antonio M, Barry N, Sigurdardottir A, Bertolotti A. 2015. Preventing proteostasis diseases by selective inhibition of a phosphatase regulatory subunit. Science 348: $239-242$.

Desplats P, Lee HJ, Bae EJ, Patrick C, Rockenstein E, Crews L, Spencer B, Masliah E, Lee SJ. 2009. Inclusion formation and neuronal cell death through neuron-to-neuron transmission of $\alpha$-synuclein. Proc Natl Acad Sci 106: 13010-13015.

Eisenberg D, Jucker M. 2012. The amyloid state of proteins in human diseases. Cell 148: 1188-1203.

Frost B, Jacks RL, Diamond MI. 2009. Propagation of tau misfolding from the outside to the inside of a cell. J Biol Chem 284: 12845-12852.

Gowers WR. 1892. Manual of diseases of the nervous system, Vol. 1. J\&A Churchill, London.

Grad LI, Guest WC, Yanai A, Pokrishevsky E, O’Neill MA, Gibbs E, Semenchenko V, Yousefi M, Wishart DS, Plotkin SS, Cashman NR. 2011. Intermolecular transmission of superoxide dismutase 1 misfolding in living cells. Proc Natl Acad Sci 108: 16398-16403.

Grad LI, Yerbury JJ, Turner BJ, Guest WC, Pokrishevsky E, O’Neill MA, Yanai A, Silverman JM, Zeineddine R, Corcoran L, et al. 2014. Intercellular propagated misfolding of wild-type $\mathrm{Cu} / \mathrm{Zn}$ superoxide dismutase occurs via exosome-dependent and -independent mechanisms. Proc Natl Acad Sci 111: 3620-3625.

Gurney ME, Pu H, Chiu AY, Dal Canto MC, Polchow CY, Alexander DD, Caliendo J, Hentati A, Kwon YW, Deng HX, et al. 1994. Motor neuron degeneration in mice that express a human $\mathrm{Cu}, \mathrm{Zn}$ superoxide dismutase mutation. Science 264: 1772-1775.

Hall AH. 1985. Guanabenz overdose. Ann Intern Med 102 787-788.

Holmes B, Brogden RN, Heel RC, Speight TM, Avery GS. 1983. Guanabenz. A review of its pharmacodynamic properties and therapeutic efficacy in hypertension. Drugs 26: 212-229.

Holmes BB, DeVos SL, Kfoury N, Li M, Jacks R, Yanamandra K, Ouidja MO, Brodsky FM, Marasa J, Bagchi DP, et al. 2013. Heparan sulfate proteoglycans mediate internalization and propagation of specific proteopathic seeds. Proc Natl Acad Sci 110: E3138-E3147.

Johnston JA, Dalton MJ, Gurney ME, Kopito RR. 2000. Formation of high molecular weight complexes of mu$\operatorname{tant} \mathrm{Cu}, \mathrm{Zn}$-superoxide dismutase in a mouse model for familial amyotrophic lateral sclerosis. Proc Natl Acad Sci 97: $12571-12576$

Jousse C, Oyadomari S, Novoa I, Lu P, Zhang Y, Harding HP, Ron D. 2003. Inhibition of a constitutive translation initiation factor $2 \alpha$ phosphatase, CReP, promotes survival of stressed cells. J Cell Biol 163: 767-775.

Jucker M, Walker LC. 2011. Pathogenic protein seeding in Alzheimer disease and other neurodegenerative disorders. Ann Neurol 70: 532-540.

Kane MD, Lipinski WJ, Callahan MJ, Bian F, Durham RA, Schwarz RD, Roher AE, Walker LC. 2000. Evidence for seeding of $\beta$-amyloid by intracerebral infusion of Alzheimer brain extracts in $\beta$-amyloid precursor proteintransgenic mice. J Neurosci 20: 3606-3611.

Kiernan MC, Vucic S, Cheah BC, Turner MR, Eisen A, Hardiman O, Burrell JR, Zoing MC. 2011. Amyotrophic lateral sclerosis. Lancet 377: 942-955.

Kojima E, Takeuchi A, Haneda M, Yagi A, Hasegawa T, Yamaki K, Takeda K, Akira S, Shimokata K, Isobe K. 2003. The function of GADD34 is a recovery from a shutoff of protein synthesis induced by ER stress: Elucidation by GADD34-deficient mice. FASEB J 17: 1573-1575.

Li JY, Englund E, Holton JL, Soulet D, Hagell P, Lees AJ, Lashley T, Quinn NP, Rehncrona S, Björklund A, et al. 2008. Lewy bodies in grafted neurons in subjects with Parkinson's disease suggest host-to-graft disease propagation. Nat Med 14: 501-503.

Luk KC, Kehm V, Carroll J, Zhang B, O’Brien P, Trojanowski JQ, Lee VM. 2012. Pathological $\alpha$-synuclein transmission initiates Parkinson-like neurodegeneration in nontransgenic mice. Science 338: 949-953.

Meyer-Luehmann M, Coomaraswamy J, Bolmont T, Kaeser S, Schaefer C, Kilger E, Neuenschwander A, Abramowski D, Frey P, Jaton AL, et al. 2006. Exogenous induction of cerebral $\beta$-amyloidogenesis is governed by agent and host. Science 313: 1781-1784.

Morimoto RI, Cuervo AM. 2014. Proteostasis and the aging proteome in health and disease. J Gerontol A Biol Sci Med Sci 69: S33-S38. 
Münch C, Bertolotti A. 2010. Exposure of hydrophobic surfaces initiates aggregation of diverse ALS-causing superoxide dismutase-1 mutants. J Mol Biol 399: 512-525.

Münch C, Bertolotti A. 2011. Self-propagation and transmission of misfolded mutant SOD1: Prion or prion-like phenomenon? Cell Cycle 10: 1711.

Münch C, Bertolotti A. 2012. Propagation of the prion phenomenon: Beyond the seeding principle. J Mol Biol 421: 491-498.

Münch C, O’Brien J, Bertolotti A. 2011. Prion-like propagation of mutant superoxide dismutase-1 misfolding in neuronal cells. Proc Natl Acad Sci 108: 3548-3553.

Neumann M, Sampathu DM, Kwong LK, Truax AC, Micsenyi MC, Chou TT, Bruce J, Schuck T, Grossman M, Clark CM, et al. 2006. Ubiquitinated TDP-43 in frontotemporal lobar degeneration and amyotrophic lateral sclerosis. Science 314: 130-133.

Nordlund A, Oliveberg M. 2008. SOD1-associated ALS: A promising system for elucidating the origin of proteinmisfolding disease. HFSP J 2: 354-364.

Novoa I, Zeng H, Harding HP, Ron D. 2001. Feedback inhibition of the unfolded protein response by GADD34mediated dephosphorylation of eIF2 $\alpha$. J Cell Biol 153: 1011-1022.

Prusiner SB. 1998. Prions. Proc Natl Acad Sci 95: 13363 13383.

Prusiner SB. 2012. Cell biology. A unifying role for prions in neurodegenerative diseases. Science 336: 1511-1513.

Prusiner SB, Woerman AL, Mordes DA, Watts JC, Rampersaud R, Berry DB, Patel S, Oehler A, Lowe JK, Kravitz SN, et al. 2015. Evidence for $\alpha$-synuclein prions causing multiple system atrophy in humans with parkinsonism. Proc Natl Acad Sci 112: E5308-E5317.

Ravits JM, La Spada AR. 2009. ALS motor phenotype heterogeneity, focality, and spread: Deconstructing motor neuron degeneration. Neurology 73: 805-811.

Reaume AG, Elliott JL, Hoffman EK, Kowall NW, Ferrante RJ, Siwek DF, Wilcox HM, Flood DG, Beal MF, Brown RJ, et al. 1996. Motor neurons in $\mathrm{Cu} / \mathrm{Zn}$ superoxide dismutase-deficient mice develop normally but exhibit enhanced cell death after axonal injury. Nat Genet 13: 43-47.

Ren PH, Lauckner JE, Kachirskaia I, Heuser JE, Melki R, Kopito RR. 2009. Cytoplasmic penetration and persistent infection of mammalian cells by polyglutamine aggregates. Nat Cell Biol 11: 219-225.

Ron D, Harding HP. 2007. eIF2a phosphorylation in cellular stress responses and disease. In Translational control in biology and medicine (ed. Mathews $\mathrm{MB}$, et al.), Cold Spring Harbor Monograph Series, pp. 345-368. Cold Spring Harbor Laboratory Press, Cold Spring Harbor, NY.

Rosen DR, Siddique T, Patterson D, Figlewicz DA, Sapp P, Hentati A, Donaldson D, Goto J, O’Regan JP, Deng HX, et al. 1993. Mutations in $\mathrm{Cu} / \mathrm{Zn}$ superoxide dismutase gene are associated with familial amyotrophic lateral sclerosis. Nature 364: 362.

Rotunno MS, Bosco DA. 2013. An emerging role for misfolded wild-type SOD1 in sporadic ALS pathogenesis. Front Cell Neurosci doi: 10.3389/fncel.2013.00253

Sanders DW, Kaufman SK, DeVos SL, Sharma AM, Mirbaha H, Li A, Barker SJ, Foley AC, Thorpe JR, Serpell LC, et al. 2014. Distinct tau prion strains propagate in cells and mice and define different tauopathies. Neuron 82: 12711288.

Schneider K, Bertolotti A. 2015. Surviving protein quality control catastrophes-From cells to organisms. J Cell Sci 128: $3861-3869$.

Shaw BF, Valentine JS. 2007. How do ALS-associated mutations in superoxide dismutase 1 promote aggregation of the protein? Trends Biochem Sci 32: 78-85.

Tsaytler P, Harding HP, Ron D, Bertolotti A. 2011. Selective inhibition of a regulatory subunit of protein phosphatase 1 restores proteostasis. Science 332: 91-94.

Valentine JS, Doucette PA, Zittin Potter S. 2005. Copperzinc superoxide dismutase and amyotrophic lateral sclerosis. Annu Rev Biochem 74: 563-593.

Vilchez D, Saez I, Dillin A. 2014. The role of protein clearance mechanisms in organismal ageing and age-related diseases. Nat Commun 5: 5659.

Wang J, Farr GW, Zeiss CJ, Rodriguez-Gil DJ, Wilson JH, Furtak K, Rutkowski DT, Kaufman RJ, Ruse CI, Yates JR, et al. 2009. Progressive aggregation despite chaperone associations of a mutant SOD1-YFP in transgenic mice that develop ALS. Proc Natl Acad Sci 106: 1392-1397.

Wang L, Popko B, Roos RP. 2011. The unfolded protein response in familial amyotrophic lateral sclerosis. Hum Mol Genet 20: 1008-1015.

Wang L, Popko B, Roos RP. 2014. An enhanced integrated stress response ameliorates mutant SOD1-induced ALS. Hum Mol Genet 23: 2629-2638.

Watts JC, Condello C, Stohr J, Oehler A, Lee J, DeArmond SJ, Lannfelt L, Ingelsson M, Giles K, Prusiner SB. 2014. Serial propagation of distinct strains of $A \beta$ prions from Alzheimer's disease patients. Proc Natl Acad Sci 111: 10323-10328.

Weser U, Miesel R, Hartmann HJ. 1989. Mummified enzymes. Nature 341: 696.

Yanamandra K, Kfoury N, Jiang H, Mahan TE, Ma S, Maloney SE, Wozniak DF, Diamond MI, Holtzman DM 2013. Anti-tau antibodies that block tau aggregate seeding in vitro markedly decrease pathology and improve cognition in vivo. Neuron 80: 402-414.

Zeineddine R, Pundavela JF, Corcoran L, Stewart EM, DoHa D, Bax M, Guillemin G, Vine KL, Hatters DM, Ecroyd $\mathrm{H}$, et al. 2015. SOD1 protein aggregates stimulate macropinocytosis in neurons to facilitate their propagation. Mol Neurodegener 10: 57-1-57-18. 


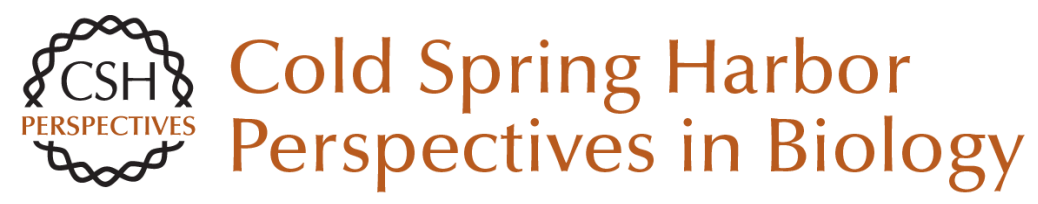

\section{Prion Properties of SOD1 in Amyotrophic Lateral Sclerosis and Potential Therapy}

Caroline Sibilla and Anne Bertolotti

Cold Spring Harb Perspect Biol 2017; doi: 10.1101/cshperspect.a024141 originally published online January 17, 2017

\section{Subject Collection Prion Biology}

\section{Genetic PrP Prion Diseases}

Mee-Ohk Kim, Leonel T. Takada, Katherine Wong, et al.

\section{Neurodegenerative Disease Transmission and}

Transgenesis in Mice

Brittany N. Dugger, Daniel P. Perl and George A. Carlson

Toward the Atomic Structure of PrPSc Jose A. Rodriguez, Lin Jiang and David S. Eisenberg

Bioassays and Inactivation of Prions Kurt Giles, Amanda L. Woerman, David B. Berry, et al.

Functional Prions in the Brain Joseph B. Rayman and Eric R. Kandel

The Amyloid Phenomenon and Its Links with Human Disease Christopher M. Dobson

Tau Positron Emission Tomography Imaging Hartmuth C. Kolb and José Ignacio Andrés

Prion-Like Polymerization in Immunity and Inflammation

Xin Cai, Hui Xu and Zhijian J. Chen
Clinical Neurology and Epidemiology of the Major

Neurodegenerative Diseases

Michael G. Erkkinen, Mee-Ohk Kim and Michael D. Geschwind

Prion Properties of SOD1 in Amyotrophic Lateral

Sclerosis and Potential Therapy Caroline Sibilla and Anne Bertolotti

Mapping Neurodegenerative Disease Onset and

Progression William W. Seeley

Erratum: Functional Prions in the Brain Joseph B. Rayman and Eric R. Kandel

Pathology of Neurodegenerative Diseases Brittany N. Dugger and Dennis W. Dickson

TIA-1 Is a Functional Prion-Like Protein Joseph B. Rayman and Eric R. Kandel

Molecular Genetics of Neurodegenerative

Dementias

Flora I. Hinz and Daniel H. Geschwind

Cross- $\beta$ Polymerization of Low Complexity

Sequence Domains

Masato Kato and Steven L. McKnight

For additional articles in this collection, see http://cshperspectives.cshlp.org/cgi/collection/

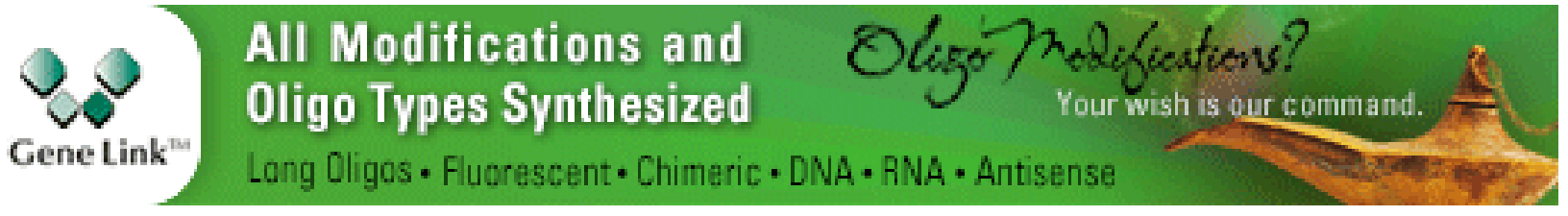


For additional articles in this collection, see http://cshperspectives.cshlp.org/cgi/collection/

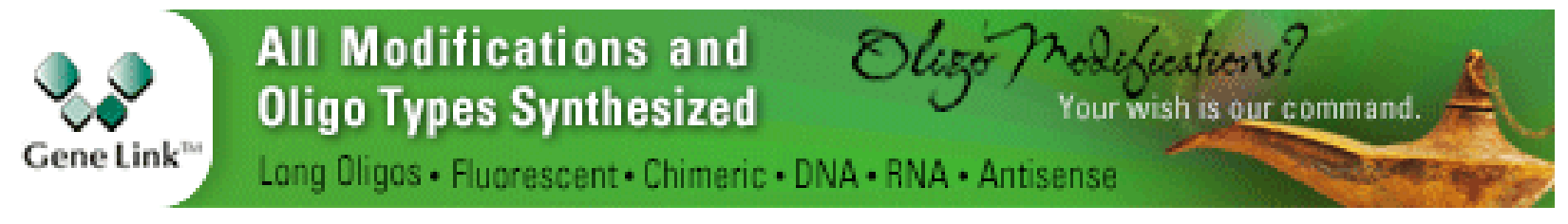

Copyright @ 2017 Cold Spring Harbor Laboratory Press; all rights reserved 